NBER WORKING PAPER SERIES

\title{
LONGER-RUN ECONOMIC CONSEQUENCES OF PANDEMICS
}

\author{
Òscar Jordà \\ Sanjay R. Singh \\ Alan M. Taylor \\ Working Paper 26934 \\ http://www.nber.org/papers/w26934
NATIONAL BUREAU OF ECONOMIC RESEARCH
1050 Massachusetts Avenue
Cambridge, MA 02138
April 2020

We are grateful to Robert Allen, Gregory Clark, Paul Schmelzing, and the Bank of England for making their datasets publicly available. All errors are ours. The views expressed herein are solely those of the authors and do not necessarily represent the views of the Federal Reserve Bank of San Francisco or the Federal Reserve System or the National Bureau of Economic Research.

At least one co-author has disclosed a financial relationship of potential relevance for this research. Further information is available online at http://www.nber.org/papers/w26934.ack

NBER working papers are circulated for discussion and comment purposes. They have not been peerreviewed or been subject to the review by the NBER Board of Directors that accompanies official NBER publications.

(C) 2020 by Òscar Jordà, Sanjay R. Singh, and Alan M. Taylor. All rights reserved. Short sections of text, not to exceed two paragraphs, may be quoted without explicit permission provided that full credit, including (C) notice, is given to the source. 
Longer-run Economic Consequences of Pandemics

Òscar Jordà, Sanjay R. Singh, and Alan M. Taylor

NBER Working Paper No. 26934

April 2020, Revised June 2020

JEL No. E43,F41,N10,N30,N40

\section{ABSTRACT}

What are the medium- to long-term effects of pandemics? How do they differ from other economic disasters? We study major pandemics using the rates of return on assets stretching back to the 14th century. Significant macroeconomic after-effects of pandemics persist for about decades, with real rates of return substantially depressed, in stark contrast to what happens after wars. Our findings are consistent with the neoclassical growth model: capital is destroyed in wars, but not in pandemics; pandemics instead may induce relative labor scarcity and/or a shift to greater precautionary savings.

Òscar Jordà

Economic Research, MS 1130

Federal Reserve Bank of San Francisco

San Francisco, CA 94105

and University of California, Davis

oscar.jorda@gmail.com

Sanjay R. Singh

Department of Economics

University of California at Davis

1122, SSH

1 Shields Avenue

Davis, CA 95616

sjrsingh@ucdavis.edu

\author{
Alan M. Taylor \\ Department of Economics and \\ Graduate School of Management \\ University of California \\ One Shields Ave \\ Davis, CA 95616-8578 \\ and CEPR \\ and also NBER \\ amtaylor@ucdavis.edu
}




\section{INTRODUCTION}

How should we think about the medium- to long-term macroeconomic effects of global pandemics? This is an important question for policymakers given the massive economic fallout from the COVID-19 outbreak. The first instinct is to draw from the experience of previous natural disasters and armed conflicts, for which the twentieth century provides ample evidence. That instinct turns out to be wrong. In this paper we use the history of major pandemics, major wars, and the rates of return since the 14th century to shed light on this problem.

In many studies of pandemics, analysis has understandably focused on short-term impacts. Even then, direct measures based on data from past episodes are not generally available (e.g., in the U.S., Meltzer, Cox, and Fukuda, 1999). An alternative would be to look at microeconomic outcomes of a given population in episodes for which high-quality administrative data are available (e.g., in Sweden, Karlsson, Nilsson, and Pichler, 2014).

Absent such data, economic historians have to use more aggregated data at the regional or national level to study the relationship between pandemic incidence and economic outcomes (e.g., the 1918 flu epidemic across U.S. states Brainerd and Siegler, 2003; Barro, Ursúa, and Weng, 2020). But again, most historical studies have typically focused on one event in one country or region and have traced local outcomes for up to a decade at most.

Of course, the most devastating pandemic of the last millennium, the Black Death, has attracted a great deal of scholarly attention. Economists and historians debate its pivotal role in economic, social, and political change, particularly in Europe. Events such as the Peasants' Rebellion in England feature centrally in a narrative of rising worker power, and the data speak to an emergence of labor scarcity seen in a positive deviation in the path of real wages. This shock left England with a $25 \%$ to $40 \%$ drop in labor supply, a roughly $100 \%$ increase in real wages, and a decline in rates of return on land from about $8 \%$ to $5 \%(C l a r k, 2007,2010)$. But it is an open question how representative the macroeconomic responses in the case of the Black Death are of large pandemics in general. 
Figure 1: Nineteen major pandemic events from the past with at least 100,000 estimated deaths

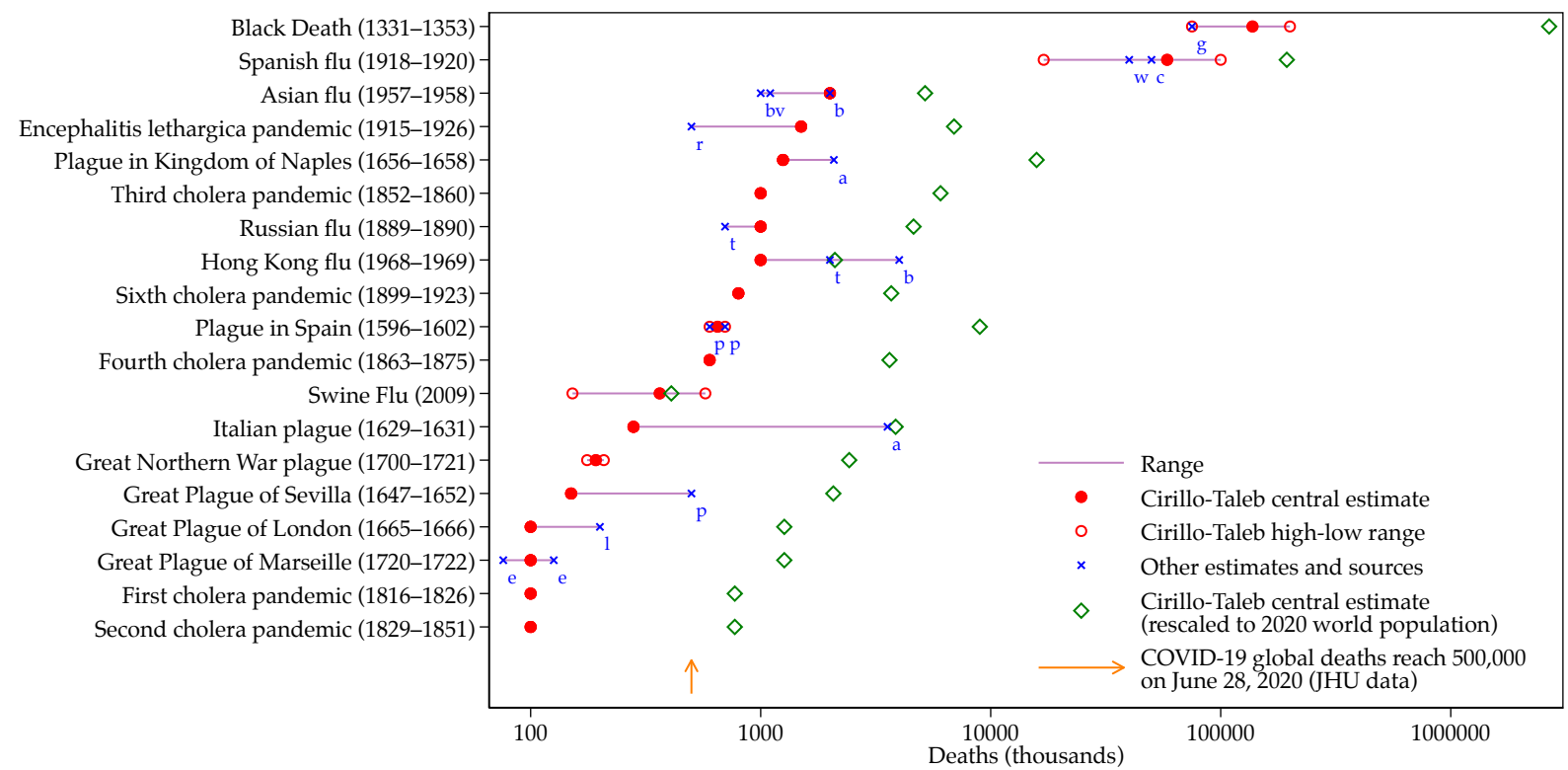

Notes: The main data are taken from the recently published study of Cirillo and Taleb (2020). See the references therein. Additional estimates of pandemic mortality are taken from: (g) George M. Gould and Walter L. Pyle. 1896. Anomalies E Curiosities of Medicine. New York: Bell; (w) Wang-Shick Ryu. 2017. Molecular Virology of Human Pathogenic Viruses. Amsterdam: Academic Press. (c) CDC. https://www.cdc.gov/flu/pandemic-resources/1918-pandemic-h1n1.html; (b) Encyclopaedia Britannica; (v) Cécile Viboud et al. 2016. Global Mortality Impact of the 1957-1959 Influenza Pandemic; Journal of Infectious Diseases 213(5):738-45; (r) R.T. Ravenholt and W.H. Foege. 1982. 1918 influenza, encephalitis lethargica, parkinsonism. Lancet 2(8303):860-864; (a) Alfani and Murphy (2017); ( $\mathrm{t}$ ) Paul V. Targonski and Gregory A. Poland. 2017. Influenza. In International Encyclopedia of Public Health, 2nd ed., edited by William C. Cockerham. Amsterdam: Academic Press. (p) Stanley G. Payne. 1973. A History of Spain and Portugal. Madison, Wisc.: University of Wisconsin Press. (1) James Leasor. 1962. The Plague and The Fire. London: George Allen and Unwin. (e) Cindy Ermus. 2015. The Plague of Provence: Early Advances in the Centralization of Crisis Management. Arcadia (9). [Arcadia Collection: Disaster Histories.]

Evidence: Past pandemic events and lessons for COVID-19. Here we take a macroeconomic view of the consequences of pandemics, and study the average effect of pandemics across all major events since the Black Death, looking at outcomes up to 40 years out. In large scale pandemics, effects will be felt across whole economies, or across wider regions, for two reasons: either because the infection itself is widespread, or because trade and market integration-in capital and/or labor markets-eventually propagates the economic shock across borders.

To that end, our focus is on European pandemics since macroeconomic data are only available in this region before modern times. We study rates of return on assets using a dataset stretching back to the 14th century, focusing on 19 major pandemic events where more than 100,000 people died. We also look at more limited evidence on real wages. The events are listed in Figure 1 and, as is clear, the inability of researchers to precisely estimate 
death tolls in past pandemics hinders our ability to consider event scaling in what follows. Even for the most famous pandemic event, the Black Death, Herlihy (1997) asserts: “The Black Death of 1348 and 1349, and the recurrent epidemics of the fourteenth and fifteenth centuries, were the most devastating natural disasters ever to strike Europe. We cannot cite exact losses; there are no global figures." Our Figure 1 shows that numerical uncertainty afflicts all death tolls up to, and including, the 2oth century. The baseline range of estimates are taken from the newly published study of Cirillo and Taleb (2020), with alternatives from other sources. For some pandemics, the range of estimates varies by a factor of 5 or 10 (e.g., The Italian Plague). Many vary by a factor of 2, such as the "small" plagues, London, Sevilla, Marseille. Estimates for the Black Death itself range from 75 to 200 million. Remarkably, even for as recent an event as the Hong Kong Flu of 1968-69, estimates vary by a factor of 4 , from 1 to 4 million. For the Cholera epidemics only a single, round number is given in sources, suggesting a rough guess. Perhaps this should be no surprise: even now in real time we see authorities, by accident or design, misreporting incorrect case and death counts for COVID-19. Further scaling problems are created across time by the varying size of the local or world population, which Cirillo and Taleb (2020) attempt to control for by scaling up death tolls in past events to a 2020 estimate using the estimated growth of world population over time. These rescaled figures are also shown in Figure 1 but they do not change the ranking materially, and they remain subject to the same wide margins or error. If anything, they tells us that there have been 17 "large pandemics" in our sample and a further 2 "super pandemics": the Black Death and the Spanish Flu. Given this discussion, we identify events purely by a binary indicator, and do not try to scale, although we do consider robustness of results to the inclusion or exclusion of the two super pandemics.

Does COVID-19 belong in this comparison group? To add context, the scenarios contemplated as early as March 16, 2020 by Ferguson et al (2020) placed COVID-19 as the most serious episode since the 1918 pandemic. Absent non-pharmaceutical interventions, these researchers estimated the death toll at 510,00o in Britain and 2.2 million in the U.S. Aggressive and recurrent suppression strategies would reduce the toll by a factor of 10 
approximately, according to these authors. ${ }^{1}$ Worldwide, that could still leave COVID-19 as the second most devastating event in over a century. As we write, global deaths totaled over 500,000 by end-June 2020, so COVID-19 will become the 2oth large pandemic event of the kind described in Figure 1, and may eventually go far beyond the 1 million mark.

Theory: The natural rate and economic mechanisms after a pandemic. Here our main interest is the response of the real natural rate of interest to a pandemic event. Introduced by Wicksell, and central to modern macroeconomic theory and empirics (Laubach and Williams, 2003; Wicksell, 1898; Woodford, 2003), the real natural rate of interest is the level of real returns on safe assets which equilibrates an economy's savings supply and investment demand-while keeping prices stable. This latent equilibrium variable can therefore serve as a useful barometer of medium-term fluctuations in economic dynamism. In stagnant societies, savings are plentiful relative to investment opportunities (relatedly, see, e.g. Summers, 2014, and his revival of the secular stagnation hypothesis). Formally, in the canonical Ramsey (1928) model of neoclassical growth, it is well known that population slowdown or greater preference to save depresses the natural rate (Rachel and Smith, 2017).

In the very long run, from century to century, the natural rate may drift slowly for technological, political, or institutional reasons. But over a horizon of around 10-20 years, medium-term deviations will dominate. Economic theory presumptively indicates that pandemics could be felt in transitory downward shocks to the natural rate over such horizons: investment demand is likely to wane, as labor scarcity in the economy suppresses the need for high investment. At the same time, savers may react to the shock with increased saving, either behaviorally as precautionary motives mount in bad times (cf. Malmendier and Nagel, 2011), or simply to replace lost wealth used up during the peak of the calamity. Indeed, 2020Q2 data for the United States showed a pronounced spike in household saving.

\footnotetext{
${ }^{1}$ However, the uncertainty around these estimates is quite large. Also, the ability and willingness of some countries to actually implement and sustain such suppression strategies properly is open to question. At the time of writing (29th June 2020), both Britain and the U.S. have put some suppression strategies to work, so the implied lower targets might yet be met, although we do not yet know how the eagerness to reopen the economy may prevent that goal from being reached as the year progresses.
} 


\section{DATA}

To study the macroeconomic responses to historic pandemic events, we use data collected over many years by many economic historians collectively, and then pulled together gradually to form a continuous time series measuring economic indicators at annual frequency in cities, regions, and countries from the 14th century to the present.

Historical interest rates from 1314 to 2018 compiled by Schmelzing (2020) are available at the Bank of England's data repository, where further details on data sources are given. The dataset covers France (1387-2018), Germany (1326-2018), Italy (1314-2018), the Netherlands (1400-2018), Spain (1400-1729, 1800-2018), and the U.K. (1314-2018). European real interest rates are constructed by weighting real interest rates on long-term debt by GDP shares (Maddison, 2010). ${ }^{2}$ The underlying assets are debt contracts "which are not contracted short-term, which are not paid in-kind, which are not clearly of an involuntary nature, which are not intra-governmental, and which are made to executive political bodies." More limited data for other time series are available for the UK in the same data repository. Data on real wages for Great Britain from 1311 to 2016 come from the real consumption wage series of Clark (2007) extended by Thomas and Dimsdale (2017). Data on real GDP per capita for England from 1311 to 2016 are obtained from the real GDP per capita at market prices series available in Thomas and Dimsdale (2017).

\section{EMPIRICAL DESIGN}

Pandemics, like natural disasters, offer a unique opportunity to study how economies work. They are like a randomized control trial, but at a much larger scale, with microbiology providing the natural assignment mechanism. Not surprisingly, our empirical approach shares similar features with such a trial. Specifically, we use history as a guide to compare the average path after a pandemic against its predicted counterfactual.

\footnotetext{
${ }^{2}$ The weighting follows Schmelzing (2020), but results are robust to alternative weightings and also hold when we employ country-specific estimation as shown below. Aggregation weights do not sway the result.
} 
Specifically, given what we observe, and using a historical sample, one can easily construct the expected value of a future counterfactual outcome of interest. Similarly, one can compute the expectation of that same outcome following pandemics. This is the key idea behind the local projections estimator that we use (Jordà, 2005).

In particular, we characterize the response of the natural rate to a pandemic as

$$
\tau(h)=E\left(r_{t+h}^{*}-r_{t}^{*} \mid P_{t}=1 ; \Omega_{t}\right)-E\left(r_{t+h}^{*}-r_{t}^{*} \mid P_{t}=0 ; \Omega_{t}\right),
$$

where $r_{t+h}^{*}-r_{t}^{*}$ refers to the change in the natural rate from the year the pandemic ends to a future time $h$ years later. $P_{t}$ is a dummy variable that is 1 if there is a pandemic ending in year $t$, and is o otherwise, and $\Omega_{t}$ refers to the information set available at time $t^{3}$

We estimate $\tau(h)$ using local projections, specifically, using the set of regressions:

$$
r_{t+h}^{*}-r_{t-1}^{*}=\alpha^{h}+\beta^{h} P_{t}+\sum_{l=1}^{L} \rho_{l}^{h} r_{t-1-l}^{*}+e_{t+h}^{h} ; h=1, \ldots, H
$$

where clearly $\hat{\tau}(h)=\hat{\beta}_{h}$. We choose 1o lags $(L=10)$ though the estimate $\hat{\beta}_{h}$ is unbiased whether we include these controls or not. ${ }^{4}$

Our estimate of the natural rate of interest, $r_{t}^{*}$, is based on the following simple state space model given the data that is available:

$$
\begin{aligned}
& r_{t}=r_{t}^{*}+u_{t}, \\
& r_{t}^{*}=r_{t-1}^{*}+v_{t} .
\end{aligned}
$$

Here, the natural rate is a latent unobserved variable that follows a random walk. Such a model is flexible enough to capture any secular trends without the need to specify them

${ }^{3}$ Most pandemics last for more than one year. We adopt as a timing convention the year when they end.

${ }^{4}$ Note that because pandemics are unpredictable and completely exogenous to the economy, we could omit $\Omega_{t}$ from the conditioning information set. $\hat{\tau}(h)$ would still be unbiased. Including right-hand side information improves the efficiency of the estimator. In other instances, when treatment is determined by observables, this will not be true. Thus $\hat{\tau}(h)$ is basically the cumulative Average Treatment Effect of the pandemic on interest rates, $h$ periods later. 
directly. The observed rate of interest $r$ fluctuates around the natural rate $r^{*}$. The error terms are assumed to be Normal and Equation 3 can be estimated using the Kalman filter and maximum likelihood methods.

\section{Results}

These tools deliver the estimate of the natural rate shown in Figure $2 a$, based on an aggregate using data from France, Germany, the Netherlands, Italy, Spain and the U.K. We simply call this aggregate "Europe." The figure displays the raw data on interest rates, along with our estimate of the natural rate of interest. Our estimates of the natural rate show the now well-documented secular trend decline over the centuries, from about 10\% in medieval times, to $5 \%$ at the start of the industrial revolution, and nowadays hovering near $\mathrm{o} \%$. It is easy to see that our estimate of the natural rate goes a long way towards addressing the considerable annual volatility seen in the raw data. Beyond measurement error, that noise also reflects wild fluctuations in harvests, armed conflict, and other events to which pre-industrial societies were exposed to a much greater degree versus today. With industrialization and modern finance, those fluctuations diminished considerably.

Figure $2 \mathrm{~b}$ contains our main result, and displays $\hat{\tau}(h)$, the response of the natural rate to a pandemic, 1 to 40 years into the future. Pandemics have effects that last for decades. Following a pandemic, the natural rate of interest declines for years thereafter, reaching its nadir about 20 years later, with the natural rate about 150 bps lower had the pandemic not taken place. At about four decades later, the natural rate returns to the level it would be expected to have had if the pandemic not taken place.

These results are staggering and speak of the disproportionate effects on the labor force relative to land (and later capital) that pandemics had throughout the centuries. It is well known that after major recessions associated with financial crises, history shows that real safe rates can be depressed for 5 to 10 years (Jordà, Schularick, and Taylor, 2013), but the responses here display even more pronounced persistence. 
Figure 2: The European real natural rate and response after pandemics

(a) European real natural rate of interest, 1315-2018

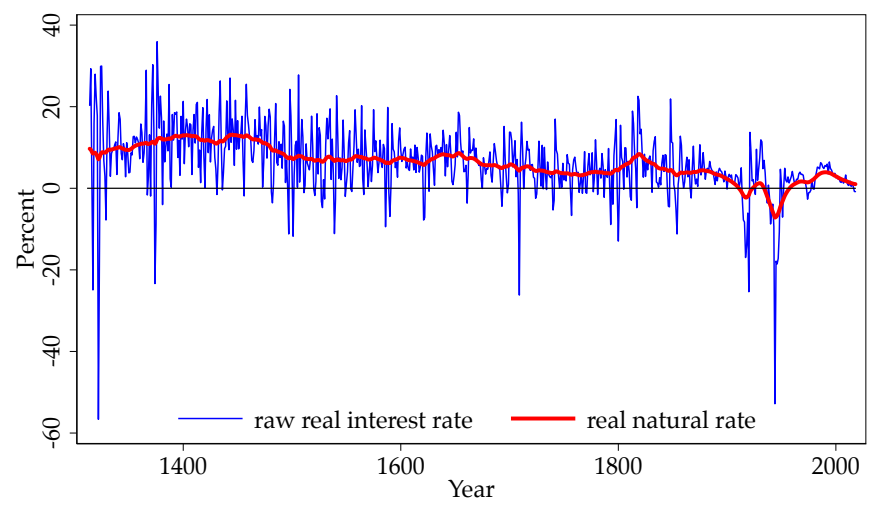

(b) Response after pandemics

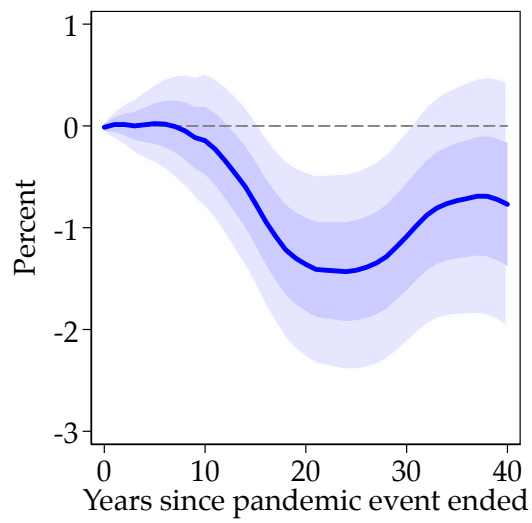

(c) Country-specific response after pandemics

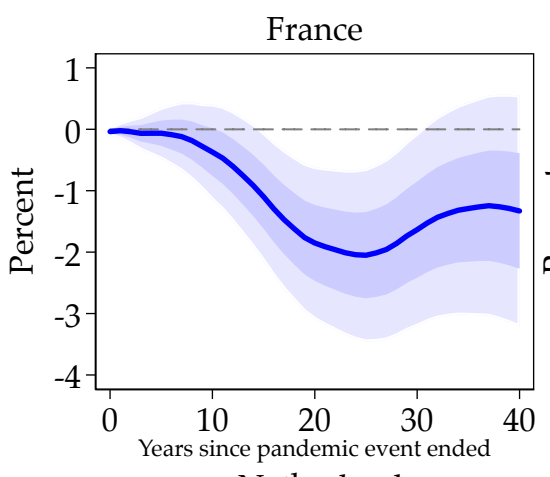

Netherlands

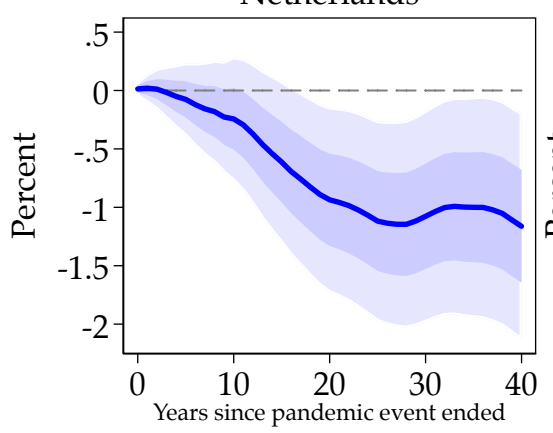

Germany

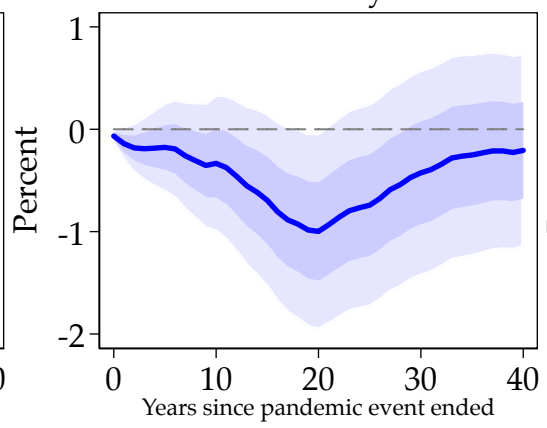

Spain

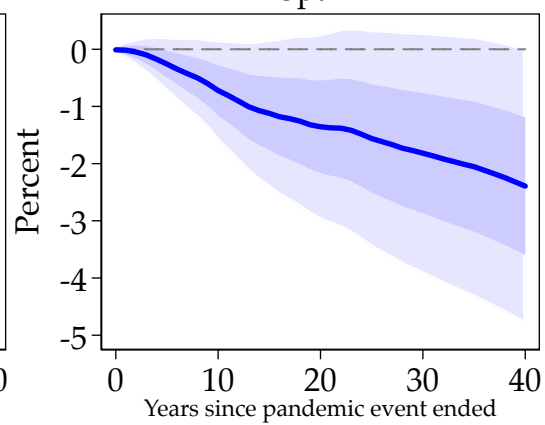

Italy

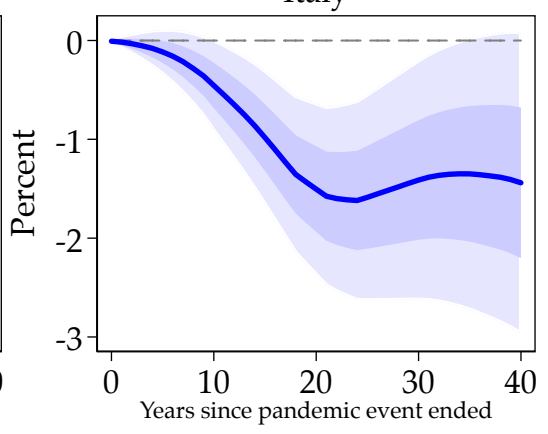

UK

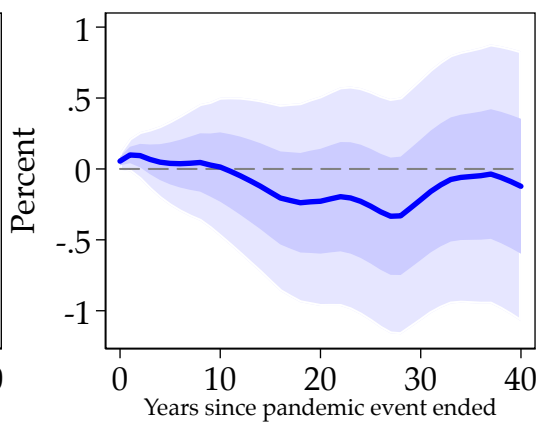

Notes: Raw interest data from Schmelzing (2020). The real rate is based on the model in Equation 3 . Response calculated using Equation 2. Shaded areas are 1 and 2 s.e. bands around response estimates. See text. 
However, did all countries in the Europe experience pandemics in the same manner shown? Is our choice of aggregation a problem? To answer that question, we turn to Figure $2 \mathrm{c}$ where we present similar responses of the natural rate for each of the component economies: France, Germany, Italy, the Netherlands, Spain, and the U.K.

The heterogeneity of the responses turns out to be informative. At one end we have countries like France, Italy, and Spain where the effects of pandemics are much larger ( $3 \%-4 \%$ for France, Italy and Spain) in contrast to the Anglo-Saxon bloc of the Germany, the Netherlands and the U.K., with far more modest effects on the natural rate.

This heterogeneity reflects, among other explanations, the timing of the pandemics across countries, the relative exposure of each country to the pandemic, the relative size of the working population, and how industrialized one economy was relative to another.

\section{PANDEMics versus wars}

A natural concern might be omitted variables, specifically the historical occurrence of other macro-salient events that could persistently disturb real interest rates. One obvious example is war. A clear confounding potential stems from the privations of wartime conditions which make diseases more likely. For example, a plague, possibly the first recorded influenza outbreak, occurred among the Athenians during the Peloponnesian War (Thucydides, 2.47-54). However, the correlation of war and disease outbreaks is far from being one.

On the other hand, for the economic indicator of interest in this study, the bias could easily go the other way. Sovereign bond markets were to a large degree an innovation whose origin was military necessity, and the fiscal state had perhaps its most important role as an instrument of war (Brewer, 1990). Yet here the burden of raising large sums via debt finance could just as easily imply higher real interest rates via conventional crowding out arguments, or via risk-premium (e.g., default) channels, or simply due to capital scarcity created by wartime physical capital destruction (a feature absent in pandemics). 
To address this concern here we control for wars, by using an indicator variable Wart which is set equal to one in any year in which war-time deaths in Europe exceed 20,000. We obtain the war-time military personnel casualties from Schmelzing (2020) dataset who draws data from Table 4.1 in Levy (1983).5,6

We then estimate an augmented local projection to include controls for war. Specifically, we estimate

$$
r_{t+h}^{*}-r_{t}^{*}=\alpha^{h}+\beta^{h} P_{t}+\gamma^{h} \text { War }_{t}+\sum_{l=1}^{L} \rho_{l}^{h} r_{t-l}^{*}+\sum_{l=1}^{L} \phi_{l}^{h} \text { War }_{t-l}+e_{t+h}^{h} ; h=1, \ldots, H
$$

where we include also the lagged values of this indicator as controls, where the coefficients $\gamma^{h}$ are the impulse response of the real interest to a war event in year 0.7

Figure 3a shows the result of this exercise. Our main finding is robust. The dynamic response of the real natural rates to pandemics is as before, and slightly amplified: lower for 30-40 years and in a statistically significant way. But as we anticipated, the effect of war goes the other way: wars tend to leave real interest rates elevated for $30-40$ years and in an economically (and statistically) significant way, as shown in panel (a) of Table 1 .

Real wages. By defining pandemics as events with 100,000 or more deaths, we have thus far identified episodes with large contractions in the labor force and, hence, in the ratio of labor to capital. We see this as one explanation for the response of the real natural rate of interest. If so, we should see a countervailing response in real wages, and this provides another consistency check. To explore whether this is indeed the case, we use a similar local projection estimator in Figure $3 \mathrm{~b}$ where instead of the real natural rate, we use real wages in Great Britain as the response variable and in the control set.

5Total number of battle deaths are divided by duration of the battle (in years) to obtain an annual series of battle deaths. Since battles lasted more than a year, sometimes more than a decade, we think 20,000 deaths per year is comparable to the pandemic death toll threshold of 100,000 we employ.

${ }^{6}$ Readers interested in the debate on severity of pre-19th century epidemics may refer to Alfani and Murphy (2017), Roosen and Curtis (2018), and Biraben (1975), among others.

${ }^{7}$ Wars often last for several years. We focus on war-year pairs with 20,000 casualties or more. Hence, to eliminate the overlapping effect of large casualties felt over consecutive years, we add up to 1o lags of our dummy variable as a right-hand side variable. 
Figure 3: Responses after pandemics and wars

(a) Response of European real natural rate

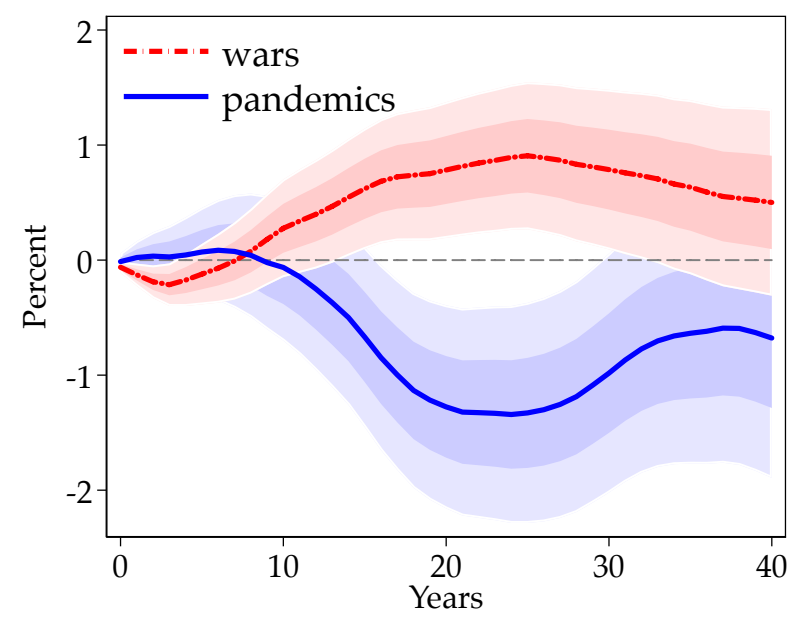

(c) Response of real GDP per capita in England

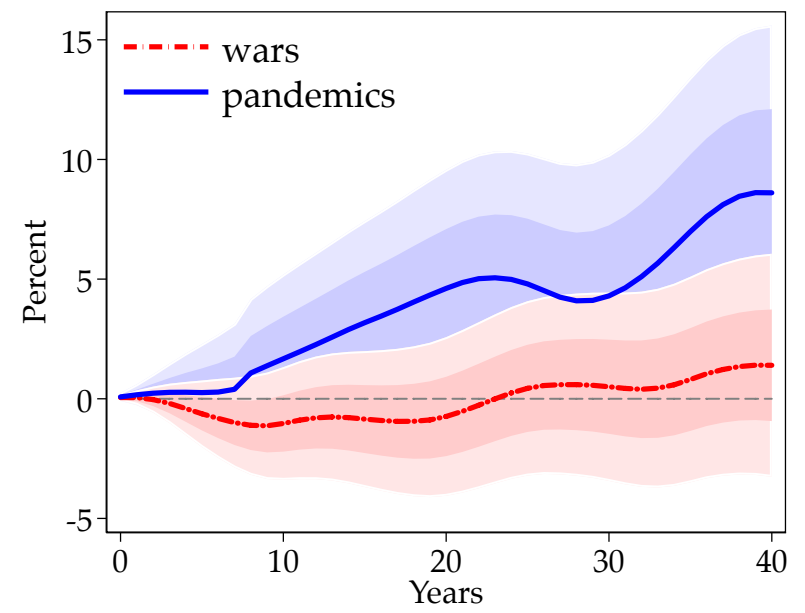

(b) Response of real wages in Great Britain

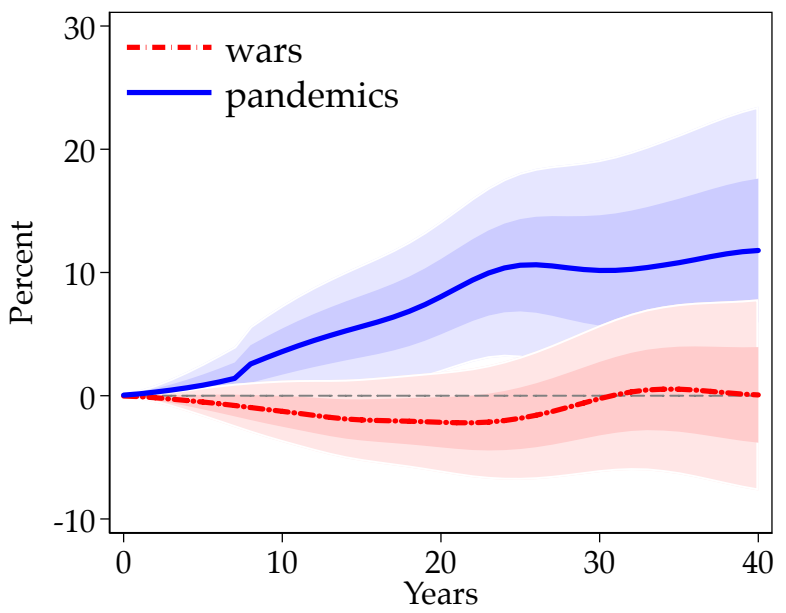

(d) Response of $r-g$ in England

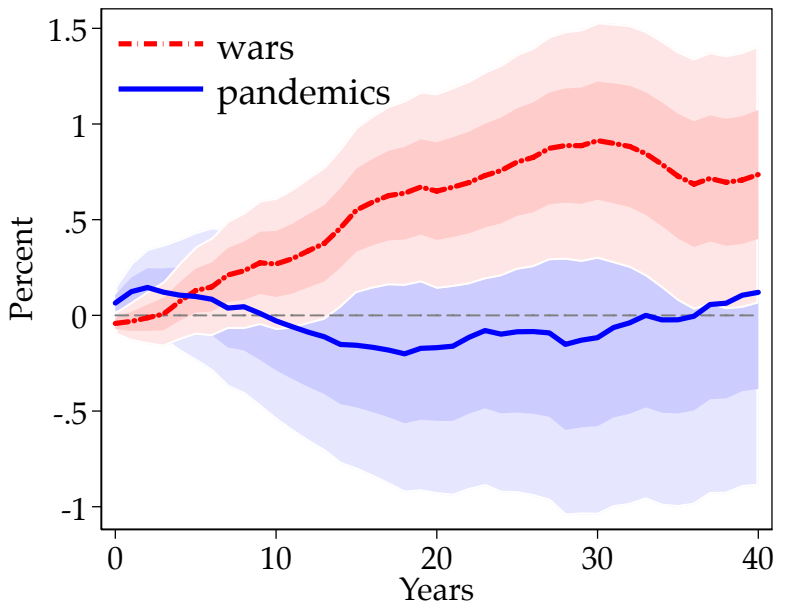

Notes: Response calculated using Equation 4. Final two panels use trends estimated for real wages in Great Britain and real GDP per capita in the UK. Details on trend estimation is provided in Appendix A. Shaded areas are 1 and 2 s.e. bands around response estimates. See text. 
Table 1: Responses after pandemics and wars

\begin{tabular}{lccccc}
\hline \hline Horizon year & $h=0$ & $h=10$ & $h=20$ & $h=30$ & $h=40$ \\
\hline \multicolumn{1}{l}{ (a) Responses of European real natural rate at years 0 to } & 40 & (change from year -1 baseline) & \\
\hline Pandemics & -0.01 & -0.06 & $-1.28^{* * *}$ & $-0.98^{*}$ & -0.68 \\
& $(0.04)$ & $(0.32)$ & $(0.44)$ & $(0.52)$ & $(0.61)$ \\
Wars & -0.06 & 0.28 & $0.78^{* * *}$ & $0.79^{* *}$ & 0.50 \\
& $(0.02)$ & $(0.21)$ & $(0.29)$ & $(0.35)$ & $(0.41)$ \\
$H_{0}:$ Pandemics $=$ Wars, $p$-value & 0.26 & 0.38 & 0.00 & 0.01 & 0.11 \\
Observations & 694 & & & & \\
\hline \hline
\end{tabular}

(b) Responses of real wages in Great Britain at years 0 to 40 (change from year -1 baseline)

\begin{tabular}{lccccc}
\hline Pandemics & 0.05 & $3.58^{*}$ & $8.04^{* * *}$ & $10.17^{* *}$ & $11.79^{* *}$ \\
& $(0.05)$ & $(1.87)$ & $(3.06)$ & $(4.48)$ & $(5.83)$ \\
Wars & -0.02 & -1.27 & -2.16 & -0.24 & 0.06 \\
& $(0.03)$ & $(1.25)$ & $(2.04)$ & $(2.98)$ & $(3.88)$ \\
$H_{0}:$ Pandemics $=$ Wars, $p$-value & 0.25 & 0.03 & 0.01 & 0.05 & 0.10 \\
Observations & 696 & & & & \\
\hline \hline
\end{tabular}

(c) Responses of real GDP per capita in England at years 0 to 40 (change from year -1 baseline)

\begin{tabular}{lccccc}
\hline Pandemics & 0.08 & 1.67 & $4.61^{*}$ & 4.30 & $8.61^{* *}$ \\
Wars & $(0.08)$ & $(1.76)$ & $(2.48)$ & $(2.95)$ & $(3.50)$ \\
& 0.05 & -1.03 & -0.74 & 0.50 & 1.40 \\
$H_{0}:$ Pandemics $=$ Wars, $p$-value & $(0.06)$ & $(1.18)$ & $(1.66)$ & $(1.97)$ & $(2.33)$ \\
Observations & 0.77 & 0.20 & 0.07 & 0.29 & 0.09 \\
\hline \hline
\end{tabular}

(d) Responses of $r-g$ in England at years 0 to 40 (change from year - 1 baseline)

\begin{tabular}{lccccc}
\hline Pandemics & 0.06 & -0.03 & -0.17 & -0.12 & 0.12 \\
Wars & $(0.04)$ & $(0.26)$ & $(0.38)$ & $(0.46)$ & $(0.51)$ \\
& -0.04 & 0.27 & $0.65^{* *}$ & $0.91^{* * *}$ & $0.74^{* *}$ \\
$H_{0}:$ Pandemics $=$ Wars, $p$-value & $(0.03)$ & $(0.17)$ & $(0.26)$ & $(0.31)$ & $(0.34)$ \\
Observations & 0.04 & 0.34 & 0.08 & 0.07 & 0.31 \\
\hline \hline
\end{tabular}

Notes: Standard errors in parentheses. See text. 
The response of real wages is in the opposite direction to the response of the real natural rate, with its effects being felt over decades. The figure shows that real wages grow gradually so that forty years out the cumulative deviation in the real wage is $+15 \%$. Contrast the response of wages after wars, which remain pretty much unchanged. A formal test of the differences is provided in panel (b) of Table 1 . These results match the predictions of the neoclassical model, and accord with historical narratives: the Black Death induced labor scarcity in the European economy, and pushed real wages up. In equilibrium, this went hand in hand with lower returns to capital.

Real GDP per capita. Finally, we display the response of real GDP per capita in Figure $3 c$ for England (the only economy for which we have long-run data). Here again, the contrast between wars and pandemics is self-evident (with formal tests provided in panel (c) of Table 1). The destruction of capital (and loss of lives) during wars, has a noticeable negative effect on labor productivity that is absent in pandemics, where in fact, labor productivity increases.

Debt sustainability and $r-g$. While the short-run fallout from pandemics looks similar to other economic disasters-large and sudden declines in economic activity-the mediumto long-run economic consequences are staggeringly different, as we have shown. And these differences matter for policymakers. In any such abrupt downturn, the textbook response is to either borrow to smooth the shock, or to pursue aggressive stimulative fiscal policy to counter the shock. Both will likely result in a rapid buildup of public debt. However, the sustainability of such debt depends crucially on the type of economic disaster confronted.

In order to illustrate this point we turn to Figure $3 \mathrm{~d}$. This figure shows the response of the real natural rate minus the growth rate of real GDP per capita, call it $r-g$, using natural rate data only for the U.K. and for real GDP per capita growth rates for England, as above. If this difference becomes more negative, it becomes easier to sustain higher levels of debt. Conversely, when this difference becomes more positive, debt sustainability becomes 
harder. Once again, we see that pandemics and wars have very different consequences in this respect as well.

Figure $3 \mathrm{~d}$ shows that in the aftermath of pandemics, $r-g$ becomes slightly negative, by about 50 basis points around the 20 year mark, before returning back to equilibrium. In contrast, wars result in a boost of about 100 basis points, peaking around the 30 year mark. Panel (d) in Table 1 shows evaluates the differences between these two paths every decade. Though the statistical evidence is not as strong as in previous experiments, the economic differences are patently clear.

\section{Robustness}

Robustness to possible major trend breaks. Schmelzing (2020) proposes three historical dates at which the trend for the real interest rate could have changed. These are the "post-Bullion famine" period following the end of the global monetary contraction (1494), the "North-Weingast" institutional revolution that led to emergence of credible public debt mechanisms in Britain (1694), and the "post-Napoleonic" founding of the modern international state system (1820). Although the state-space model from Equation 3 is sufficiently flexible, to confirm that our results are not affected by such shifts, we add controls for time trends starting at these historical dates. Figure 4a plots the new estimated response of the European real natural rate following a pandemic event. As the figure shows, our baseline result is largely unchanged. The trough is similar and happens at about the same time.

Robustness when excluding small and localized pandemics. The plagues of London, Sevilla, and Marseille in Figure 1 were largely localized, not affecting the wider European region very much. Some other plagues had relatively small death totals. One may therefore be concerned that these relatively smaller events could attenuate the response of the aggregate European real natural rate. Figure $4 \mathrm{~b}$ recalculates the response of the real rate 
Figure 4: Response of real natural rate: robustness

(a) Allowing for trend breaks

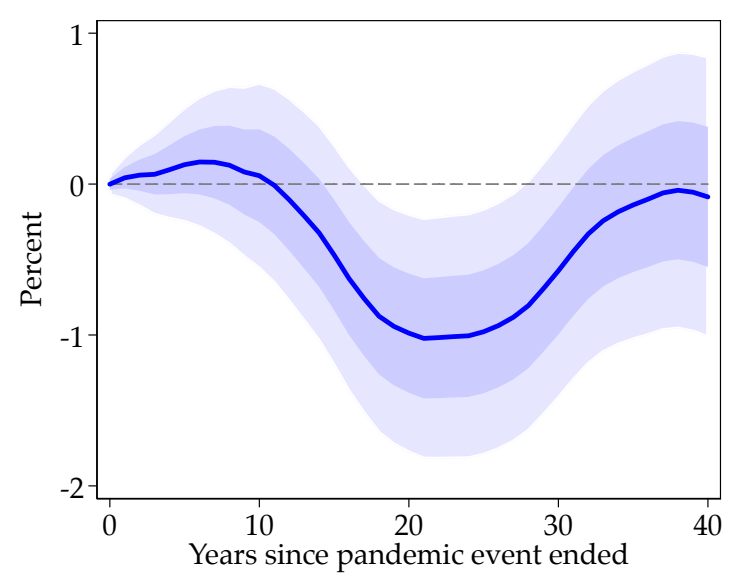

(b) Excluding local pandemics

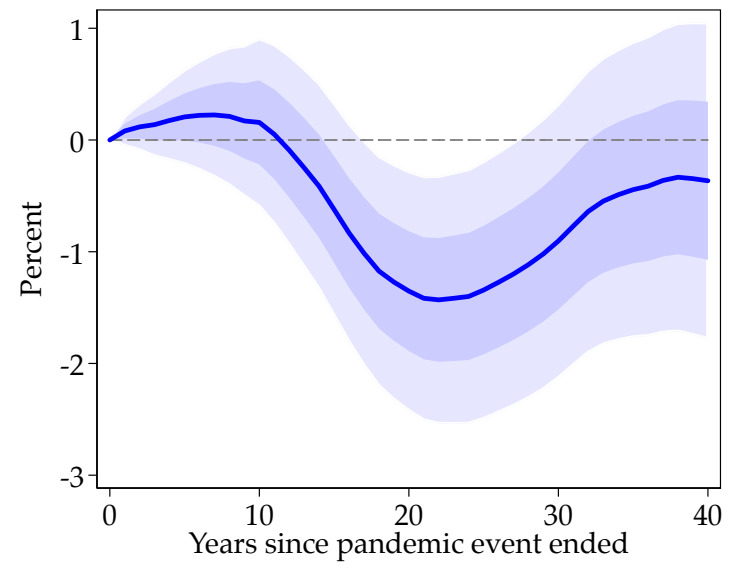

(c) Excluding the Black Death and the Spanish Flu

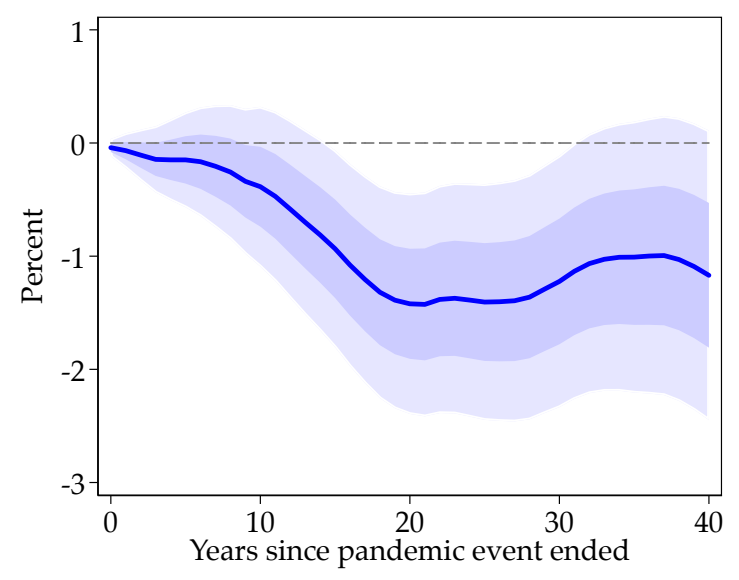

Notes: Response calculated using Equation 2. Shaded areas are 1 and 2 s.e. bands around response estimates. See text. 
when omitting the five smallest pandemics in Figure 1. The peak response in the real natural rate is slightly larger when estimated with the remaining "global" pandemics, as one would expect. These smaller pandemics exerted a smaller influence on the real rate.

Robustness when excluding the Black Death and the Spanish Flu events. Finally, in Figure 4 we consider removing from the sample the two largest events in history, the Black Death and the Spanish Flu. The resulting response is presented in Figure 4c. The Black Death stands out for having decimated the European population, thus having an outsize weight in explaining the decline of the natural rate. Although the Spanish Flu was not quite as deadly as the Black Death, it came on the heels of WWI and was followed ten years later by the Great Depression. Naturally one might worry that the decline in the natural interest rate was due to the Great Depression and not the pandemic. However, as Figure $4 \mathrm{C}$ shows, removing these two influential events from the sample does not affect our main result materially.

\section{Conclusions}

Summing up our findings, the great historical pandemics of the last millennium have typically been associated with subsequent low returns to assets, as far as the limited data allow us to conclude. These responses are huge. Smaller responses are found in real wages, but still statistically significant, and consistent with the baseline neoclassical model.

Measured by deviations in a benchmark economic statistic, the real natural rate of interest, these responses indicate that pandemics are followed by sustained periods-over multiple decades-with depressed investment opportunities, possibly due to excess capital per unit of surviving labor, and/or heightened desires to save, possibly due to an increase in precautionary saving or a rebuilding of depleted wealth. Either way, if the trends play out similarly in the wake of COVID-19 then the global economic trajectory will be very different than was expected only a few months ago. 
Should we expect declines of $1.5 \%-2 \%$ in the real natural rate, however? There may be at least three factors that could possibly attenuate the decline of the natural rate predicted by our analysis, but their presence and magnitude is uncertain and unknowable until therapies to fight COVID-19 are more developed. First, the death toll of COVID-19 relative to the total population might be smaller than in the worst pandemics of the past, but we cannot know for sure at this point. Second, COVID-19 primarily affects the elderly, who are no longer in the labor force and tend to save relatively more than the young, so the demographic channels could be altered, although the recent pick up in infections is now affecting younger individuals. Third, aggressive counter-pandemic fiscal expansion will boost public debt further, reducing the national savings rate and this might put upward pressure on the natural rate, even though our analysis suggests that this expansion of public debt should be easier to sustain in the long-run. 


\section{REFERENCES}

Alfani, Guido, and Tommy E. Murphy. 2017. Plague and Lethal Epidemics in the Pre-Industrial World. The Journal of Economic History 77(1): 314-343.

Barro, Robert J., José F. Ursúa, and Joanna Weng. 2020. The Coronavirus and the Great Influenza Pandemic: Lessons from the "Spanish Flu" for the Coronavirus's Potential Effects on Mortality and Economic Activity. Technical Report 26866, NBER working paper.

Biraben, Jean-Noël. 1975. Les hommes et la peste en France et dans les pays européens et méditerranéens. Tome I: la peste dans l'histoire. Paris: Mouton.

Brainerd, Elizabeth, and Mark Siegler. 2003. The Economic Effects of the 1918 Influenza Epidemic. CEPR Discussion Paper 3791.

Brewer, John. 1990. The Sinews of Power: War, Money, and the English State, 1688-1783. Cambridge, Mass.: Harvard University Press.

Cirillo, Pasquale, and Nassim Nicholas Taleb. 2020. Tail risk of contagious diseases. Nature Physics $1-8$.

Clark, Gregory. 2007. The long march of history: Farm wages, population, and economic growth, England 1209-1869. Economic History Review 60(1): 97-135.

Clark, Gregory. 2010. The macroeconomic aggregates for England, 1209-2008. Research in Economic History 27: 51-140.

Ferguson, Neil, et al. 2020. Impact of non-pharmaceutical interventions (NPIs) to reduce COVID-19 mortality and healthcare demand. https://www.imperial.ac.uk/media/imperialcollege/medicine/sph/ide/gida-fellowships/Imperial-College-COVID19-NPI-modelling-16-032020.pdf.

Herlihy, David. 1997. The Black Death and the Transformation of the West. Harvard University Press.

Jordà, Òscar. 2005. Estimation and inference of impulse responses by local projections. American Economic Review 95(1): 161-182.

Jordà, Òscar, Moritz Schularick, and Alan M. Taylor. 2013. When credit bites back. Journal of Money, Credit and Banking 45(s2): 3-28.

Karlsson, Martin, Therese Nilsson, and Stefan Pichler. 2014. The impact of the 1918 Spanish flu epidemic on economic performance in Sweden: An investigation into the consequences of an extraordinary mortality shock. Journal of Health Economics 36(C): 1-19.

Laubach, Thomas, and John C. Williams. 2003. Measuring the natural rate of interest. Review of Economics and Statistics 85(4): 1063-1070.

Levy, Jack S. 1983. War in the Modern Great Power System: 1495-1975. Lexington, Ky.: University Press of Kentucky.

Maddison, Angus. 2010. Historical statistics on world population, GDP and Per Capita GDP, 1-2008 AD. University of Groningen. 
Malmendier, Ulrike, and Stefan Nagel. 2011. Depression babies: do macroeconomic experiences affect risk taking? The Quarterly Journal of Economics 126(1): 373-416.

Meltzer, Martin I., Nancy J. Cox, and Keiji Fukuda. 1999. The economic impact of pandemic influenza in the United States: priorities for intervention. Emerging Infectious Diseases 5(5): 659-671.

Rachel, Łukasz, and Thomas D. Smith. 2017. Are low real interest rates here to stay? International Journal of Central Banking 13(3): 1-42.

Ramsey, Frank Plumpton. 1928. A mathematical theory of saving. Economic Journal 38(152): 543-559.

Roosen, Joris, and Daniel R Curtis. 2018. Dangers of noncritical use of historical plague data. Emerging Infectious Diseases 24(1): 103-110.

Schmelzing, Paul. 2020. Eight centuries of global real interest rates, $r-g$, and the 'suprasecular' decline, 1311-2018. Bank of England Staff Working Paper 845.

Summers, Lawrence H. 2014. Economic prospects: Secular stagnation, hysteresis, and the zero lower bound. Business Economics 49(2): 65-73.

Thomas, Ryland, and Nicholas Dimsdale. 2017. A Millennium of UK Data: Bank of England OBRA dataset.

Thucydides. 1881. History of the Peloponnesian War. Oxford: Clarendon Press. Edited and translated by Benjamin Jowett.

Wicksell, Knut. 1898. Interest and Prices: A Study of the Causes Regulating the Value of Money. Jena: Gustav Fischer.

Woodford, Michael. 2003. Interest and Prices: Foundations of a Theory of Monetary Policy. Princeton, N.J.: Princeton University Press. 


\section{A. Appendix: Estimation of tRends}

We use the following state-space system, presented in Equation 3, to estimate trends for log real wages and log real GDP per capita. Let $y_{t}$ be the variable whose potential trend $y_{t}^{*}$ is to be estimated, where $g_{t}$ is the growth rate of the potential trend.

$$
\begin{aligned}
\hat{y}_{t} & =y_{t}-y_{t}^{*}, & & (\text { gap }) \\
y_{t}^{*} & =y_{t-1}^{*}+g_{t-1}+u_{y, t}^{*}, & & (\text { potential }) \\
g_{t} & =g_{t-1}+u_{g, t} . & & \text { (potential growth) }
\end{aligned}
$$

Figure Ai shows the estimated trend for real wages and real GDP per capita.

Figure A1: Estimated trends of log real wages and log real GDP per capita in the UK

(a) Real wages in Great Britain

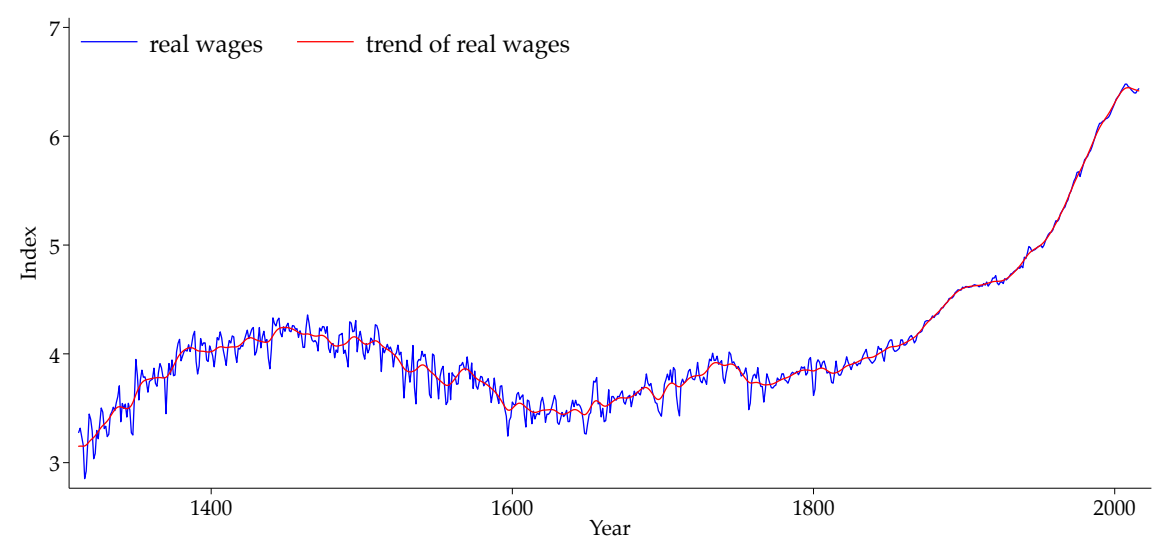

(b) Real GDP per capita in England

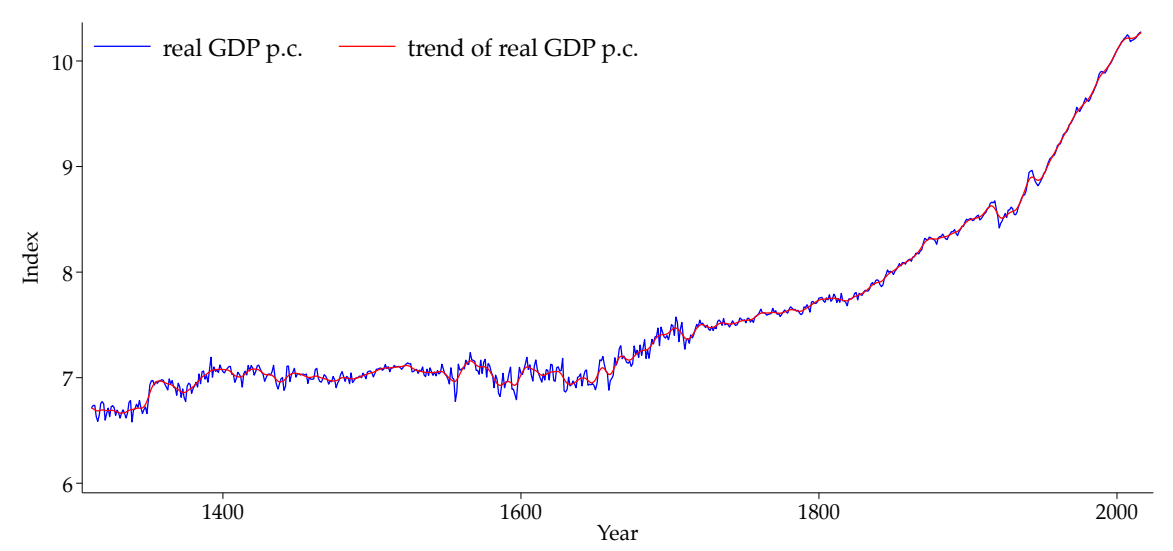

Notes: Raw data for real wages in Great Britain and real GDP per capita of England are obtained from Thomas and Dimsdale (2017). Trends estimated with a state-space system following Laubach and Williams (2003), presented in Equation 5. Real GDP per capita series is based on market prices and is quoted in " $\mathrm{mn}$, chained volume measure, 2013 prices." Real wages are in the form of an index where 1900 real wages are normalized to 100. In the graphs presented, these series are plotted on log-scale. 